\title{
Corrosão de refratários utilizados na siderurgia. Parte III: Caracterização de refratários comerciais
}

\section{(Corrosion of refractories used in steel metallurgy. Part III: Characterization of commercial refractories)}

\author{
S. R. Bragança \\ Universidade Federal do Rio Grande Sul - DEMAT/UFRGS, Av. Osvaldo Aranha 99/705, \\ Porto Alegre, RS 90035-190 \\ saulorb@ufrgs.br
}

\begin{abstract}
Resumo
Foi realizada uma revisão dos principais aspectos encontrados na literatura especializada sobre corrosão de refratários, avaliando-se a viabilidade de determinados ensaios e relacionando-se com resultados experimentais. As propriedades físicas e microestruturais de refratários comerciais foram estudadas, considerando-se as diferenças entre elas e implicações com a qualidade e provável vida útil do refratário. Assim, investigou-se os diversos tipos de refratários utilizados como revestimento em uma panela de aço, como de sobre-linha (freeboard), linha de escória e linha de metal. Os refratários magnésia-carbono e doloma-carbono foram avaliados, destacando-se também as diferenças entre eles. Os materiais analisados mostraram características favoráveis a uma elevada resistência ao processo de corrosão, apresentando uma série de propriedades a serem escolhidas de acordo com a prática industrial. Palavras-chaves: refratários, corrosão, aciaria, microestrutura
\end{abstract}

\begin{abstract}
The main aspects found in the literature about refractories corrosion were reviewed, evaluating the feasibility of certain tests and relating them with experimental results. The physical properties and microstructure of commercial refractories were analyzed, considering the differences between them and the quality implications and probable life of the refractory. Thus, this study comprised various types of refractories used as lining on steel ladle, as on freeboard, slag line and metal line. Magnesia-carbon and dolomacarbon refractories were analyzed, highlighting the differences between them. The examined materials showed characteristics favoring high resistance to corrosion process, presenting a series of properties to be selected in accordance with industry practice. Keywords: refractory, corrosion, steelmaking, microstructure
\end{abstract}

\section{INTRODUÇÃO}

Um fabricante de refratários pode optar por uma série de características ao se projetar um tijolo refratário. Por exemplo, pode-se variar a quantidade e o tipo de carbono (amorfo e/ou grafite), a distribuição de tamanho de partículas, a quantidade de partículas sinterizadas e/ou eletrofundidas, tipo de aditivos, como antioxidantes, ou até optar por não utilizar antioxidantes, e, ainda, escolher o sistema de ligação por piche e/ou resinas. Estas escolhas vão depender da adaptação necessária do refratário às características de processo e do local (linha de escória ou linha de metal) no qual ele será utilizado, além da opção "estratégica" dos produtores, em concordância com a dos usuários de refratários. A seleção de refratários também considera a "tradição" de uso em determinada empresa, como a escolha de refratários moldados ou não moldados [1].

Para cada aciaria e, especificamente, em cada região da panela de aço, os técnicos da empresa fornecedora podem projetar a microestrutura dando ênfase a algum fator que aumente a resistência à corrosão (diminuição da molhagem, da descarbonetação, etc). Em alguns casos, pode-se priorizar a resistência ao choque térmico, pelo aumento da porosidade, grosso modo, em detrimento da resistência à corrosão. Em geral, produtores e consumidores de refratários trabalham em conjunto para o aumento de produção, uma vez que o custo dos refratários está associado à quantidade de aço produzido. As metas de produção variam em $5-15 \mathrm{~kg}$ refratários por tonelada de aço manufaturado.

As propriedades microestruturais dos refratários, como qualidade dos agregados, tipo de carbono, tipos de antioxidantes, etc, foram analisadas na primeira parte desta série de artigos [2]. As propriedades físicas dos refratários e dos fatores operacionais foram estudadas na segunda parte, relacionando-se a corrosão com as propriedades das escórias [3]. Nesta terceira parte, foram examinadas as propriedades físicas e microestruturais de refratários comerciais. Investigaram-se os refratários magnésiacarbono utilizados como revestimento em uma panela de 
aço, na sobre-linha (freeboard), linha de escória e linha de metal, sendo discutido o desempenho dos refratários de linha escória na prática industrial. A análise e caracterização microestrutural de refratários doloma-carbono utilizados em linha de escória finaliza o trabalho.

\section{MATERIAIS E MÉTODOS}

Os materiais refratários analisados neste trabalho são os tijolos novos (antes do uso) de magnésia-carbono e doloma-carbono utilizados em panelas para refino de aço. Eles podem ser descritos como tijolos constituídos por magnésia/doloma sinterizada e grãos eletrofundidos, carbono de 5-15\%, agentes antioxidantes, ligados a piche e curados e/ou resinados e curados. Estes refratários são utilizados em diferentes aciarias, priorizando aqui a avaliação dos refratários utilizados para os tipos aço de maior quantidade de produção.

A Fig. 1 mostra o desenho esquemático da panela com as regiões onde se encontram os diferentes tipos de refratários analisados.

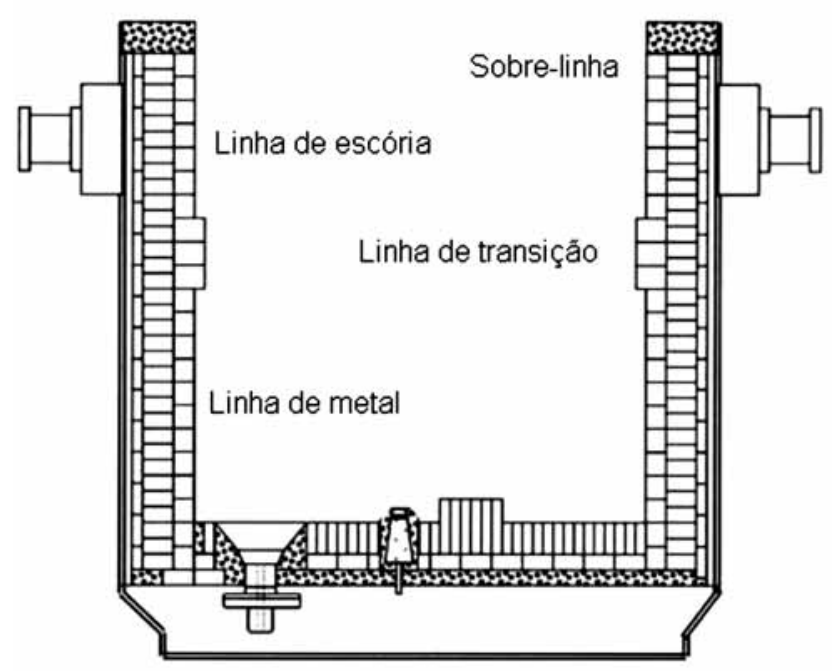

Figura 1: Panela de aço.

[Figure 1: Steel ladle.]

Os dados de caracterização dos refratários foram baseados nas normas técnicas ASTM [4-6]. Assim, procederam-se os ensaios de tenacidade à fratura, módulo de ruptura à flexão e à compressão, porosidade aparente, densidade aparente e absorção de água (querosene) e choque térmico.

A análise por microscopia eletrônica de varredura foi realizada em MEV Jeol JSM-5800 e a microanálise química por microssonda de energia dispersada EDS Noran. As amostras foram obtidas por corte a seco e quando necessário, uso de óleo mineral como líquido refrigerante. $\mathrm{O}$ polimento foi igualmente realizado a seco, para evitar qualquer risco de hidratação, sendo as amostras mantidas em dessecador à vácuo. Este cuidado é fundamental principalmente para as amostras de doloma-C.

\section{RESULTADOS E DISCUSSÃO}

Primeiramente, analisaram-se as propriedades tecnológicas dos tijolos, como porosidade e resistência mecânica. Após, realizou-se a análise microestrutural dos tijolos MgO-C de sobre-linha, linha de metal e linha de escória. Finalizou-se com a caracterização do refratário doloma-C de linha de escória.

\section{Avaliação das características tecnológicas dos refratários}

Os testes de caracterização tecnológica tiveram como objetivo verificar se os tijolos apresentavam parâmetros próximos aos especificados pelos fabricantes e, em alguns testes, como tenacidade e resistência ao choque térmico, fornecer maior conhecimento da estrutura dos tijolos. A Tabela I apresenta os dados de caracterização dos tijolos, cujos tipos são descritos abaixo: Mag 1: tijolo refratário de magnésia-carbono com magnésia eletrofundidae de magnésia sinterizada, 9-12\% de carbono, antioxidantes, ligado a piche e curado. Mag 2: Tijolo refratário de magnésia-carbono de magnésia sinterizada e grãos eletrofundidos, ligado a piche e curado, presença de grafita de alta pureza e de agentes antioxidantes. Aproximadamente 10\% de carbono. Mag 3: Tijolo refratário de magnésia-carbono, com 16\% de carbono, à base de magnésia sinterizada, grafita lamelar e magnésia eletrofundida, com adição de antioxidante, ligado à resina $\mathrm{e}$ curado. Mag 4 Tijolo magnesia-carbono ligado a piche, feito com blendas de magnésia fundida de alto grau de pureza com grafite em flocos. Mag 5: Tijolo refratário de magnésiacarbono com magnésia eletrofundida, quimicamente ligado e curado,10-13\% de carbono. Dol 1: Tijolo refratário de doloma-carbono com dolomita sinterizada, 5,5-7,5\% de carbono, ligado a piche e impregnado. Dol 2: tijolo refratário de doloma-carbono à base de dolomita sinterizada, quimicamente ligado, carbono total de $4,5 \%$.

A caracterização tecnológica mostrou que os refratários possuem qualidades compatíveis e otimizadas perante as condições de operação que se destinam. Não se verificou diferenças significativas entre os refratários analisados, como já indicava os dados da ficha técnica dos tijolos. Testes realizados em laboratório mostraram dados próximos aos fornecidos pelo fabricante. Notadamente, a resistência à compressão é menor para os tijolos ligados a piche, em comparação com os quimicamente ligados (resinados).

As principais solicitações mecânicas as quais ficam submetidos os revestimentos refratários são de compressão, sendo que as "resistências desses tijolos são mais que suficientes", de acordo com a literatura [7]. As resistências à flexão são adequadas, ao passo que a tenacidade à fratura mostrou ser elevada, bem superior a materiais de construção como o concreto. $\mathrm{O}$ teste de resistência ao choque térmico mostra que mesmo baixa $(\sim 1,2 \mathrm{MPa})$ ainda há resistência mecânica após os ensaios, isto é relevante, considerando-se à severidade do teste, bem mais crítico do que as condições de serviço. 
Tabela I - Caracterização tecnológica de tijolos comerciais utilizados em linha de escória.

[Table I - Technological characterization of commercial bricks used in slag line.]

\begin{tabular}{|c|c|c|c|c|c|c|c|}
\hline Parâmetros & Mag 1 & Mag 2 & Mag 3 & Mag 4 & Mag 5 & Dol 1 & Dol 2 \\
\hline Abs. de querosene (\%) & 0,82 & 0,93 & & & & 0,92 & \\
\hline Poros. aparente $(\%)$ & 2,55 & $4,8 / 5,5 *$ & $2,5-5^{*}$ & $4^{*}$ & $2-5^{*}$ & 2,62 & $4^{*}$ \\
\hline Dens. Ap. $\left(\mathrm{g} / \mathrm{cm}^{3}\right)$ & 3,0 & $3,08 / 3,0 *$ & $3^{*}$ & $3,02 *$ & $3 *$ & 3,1 & $2,92 *$ \\
\hline Res. à compr. (MPa) & 36 & $28 / 25^{*}$ & $30-65^{*}$ & 30 & $40-80 *$ & 22 & $47 *$ \\
\hline Res. à flexão (MPa) & 11 & 6 & & & & 5,5 & \\
\hline Tenacidade à fratura $\left(\mathrm{MPa} \mathrm{m}^{1 / 2}\right)$ & 2,2 & & & & & 1,6 & \\
\hline Res. a flexão após 5 choq. térm. (MPa) $* *$ & 1,2 & 1,3 & & & & & \\
\hline
\end{tabular}

As análises de caracterização física à temperatura ambiente fornecem poucos subsídios para se explicar as diferenças de comportamento entre refratários, advindos de diferentes fornecedores. Mesmo dados de resistência mecânica a quente, quando fornecidos, são pouco úteis para se selecionar refratários. Isto se deve ao fato que é consenso na literatura que a principal característica de um refratário deva ser a resistência à corrosão [8-11]. Assim, ressalta-se a importância da caracterização microestrutural de refratários, como forma de melhor compreender as propriedades deles frente à corrosão.

\section{Análise microestrutural de refratários comerciais antes do uso}

Procurou-se realizar a caracterização dos diversos refratários utilizados na panela aço, em particular, na linha de metal, linha de escória e sobre-linha. Atenção especial é dada aos refratários da linha de escória, por serem os refratários que sofrem mais corrosão. Além, da caracterização, realizouse também uma análise comparativa de refratários advindos de diferentes fornecedores.

\section{Caracterização dos refratários $\mathrm{MgO}-\mathrm{C}$ da sobre-linha}

A Fig. 2 mostra uma boa distribuição entre agregados grandes, alguns de tamanho superior a $2 \mathrm{~mm}$, médios e finos. Os agregados são partículas sinterizadas, possuindo a porosidade característica dos mesmos. A matriz é constituída de partículas finas de magnésia e carbono. Este está principalmente na forma de flocos de grafite. A matriz possui também partículas de alumínio, usualmente utilizadas como antioxidante. Tais partículas estão bem distribuídas e em quantidade apreciável, sendo uma característica que o fabricante projetou para o aumento da resistência à oxidação do carbono. Observa-se que a presença de antioxidantes e/ou grafite, nem sempre constam na descrição dos fabricantes, porém podem ser muito importantes para explicar o melhor desempenho de um refratário [2]. Dependendo do tipo de aciaria/aço, as características do tijolo de sobre-linha podem mudar, diminuindo-se o custo do mesmo para condições brandas de oxidação e corrosão. Por outro lado, aciarias que utilizam degaseificação por vácuo (VOD, AOD), como a do

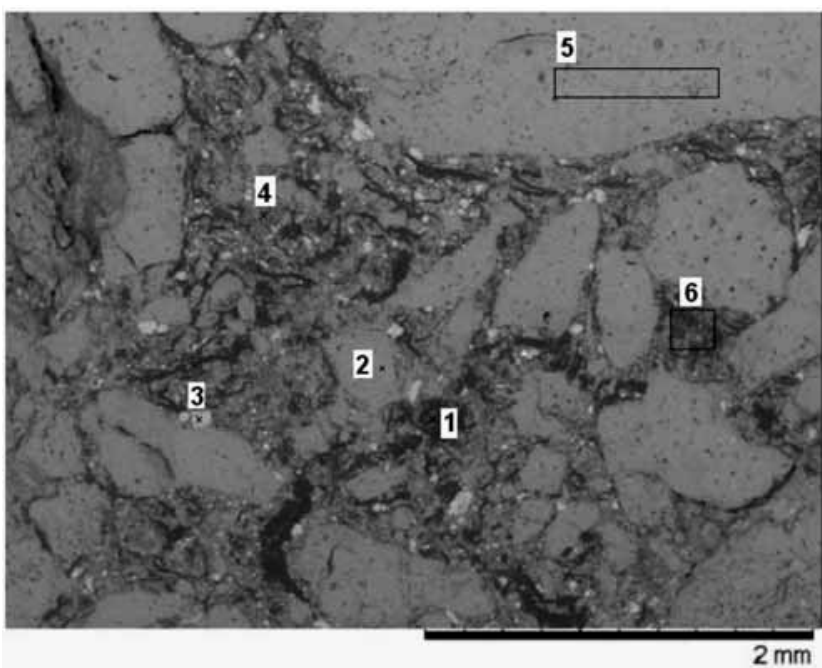

Figura 2: Tijolo $\mathrm{MgO}-\mathrm{C}$ da sobre-linha. Pontos e áreas de análise via EDS (Tabela II).

[Figure 2: $\mathrm{MgO}-\mathrm{C}$ freeboard brick. Points and areas of EDS analysis (Table II).]

Tabela II - Análise EDS de acordo com os pontos indicados na Fig. 2. Tijolo sobre-linha $\mathrm{MgO}-\mathrm{C}$.

[Table II - EDS analysis according to the points indicated in Fig. 2. Freeboard brick $\mathrm{MgO}-\mathrm{C}$.]

\begin{tabular}{ccccccc}
\hline $\begin{array}{c}\text { Elementos } \\
(\%)\end{array}$ & 1 & 2 & 3 & 4 & 5 & 6 \\
\hline $\mathrm{Mg}$ & 2,9 & 31,9 & 11,0 & 28,6 & 42,5 & 11,2 \\
$\mathrm{O}$ & 12,4 & 39,4 & 22,2 & 36,4 & 42,4 & 26,0 \\
$\mathrm{C}$ & 83,1 & 16,9 & 34,2 & 32,2 & 12,3 & 59,4 \\
$\mathrm{Al}$ & 1,3 & 4,6 & 30,5 & 2,1 & 1,9 & 2,3 \\
$\mathrm{Si}$ & 0,2 & 5,0 & 0,8 & & 0,3 & 1,0 \\
$\mathrm{~K}$ & & 0,3 & & & & \\
$\mathrm{Ca}$ & & 0,8 & 0,5 & & 0,5 & 0,1 \\
$\mathrm{Fe}$ & & 1,12 & 0,7 & & & \\
\hline
\end{tabular}

material analisado aqui, podem apresentar maior contato da escória na região de sobre-linha, de modo que os tijolos tendem a incorporar elementos e características de tijolos de linha de escória, como grafite e antioxidantes, para garantir 
uma maior resistência e, consequentemente, maior vida útil.

A análise em EDS na Fig. 2 e Tabela II identifica os seguintes pontos: 1- Partícula de carbono, como grafite. 2-Agregado: principalmente magnésio, mas também algumas impurezas como Si e Fe. 3- Partícula de alumínio (antioxidante).4-Matriz: partícula de magnésia.5-Agregado: a área analisada mostra além de magnésia, um baixo teor de impurezas. 6- Matriz: principalmente carbono e magnésia. Baixo teor de impurezas como Si e Ca. Apresentou $\mathrm{Al} \sim 2 \%$.

\section{Caracterização dos refratários $\mathrm{MgO}-\mathrm{C}$ da linha de metal}

Ao se observar as microestruturas apresentadas nas Figs. 3 e 4 , nota-se a presença de agregados de tamanho grande, mas também a presença de considerável quantidade de partículas menores. Em uma linha de metal, dependo das condições de desgaste mecânico e corrosivo, isto pode influenciar decisivamente na vida útil do refratário. Como é sabido, partículas pequenas possuem menor resistência à corrosão, pela maior razão área superficial/volume. Nota-se também que este tijolo possui agregados eletrofundidos, em destaque na Fig. 3. Salienta-se que a utilização desses é descrita na literatura como benéfica a uma maior resistência à corrosão [2]. No caso particular deste agregado eletrofundido, há uma grande quantidade de impurezas, de modo que muitas partículas (ou grãos) não possuem ligação direta entre si, podendo-se dizer que elas estão separadas pelas impurezas. $\mathrm{O}$ aspecto destas sugere que as mesmas devem ter passado pelo estado líquido durante o processamento das matériasprimas, vindo a se acumularem nos contornos de grão. Isto é desfavorável à resistência da corrosão, logo, este agregado é de pior qualidade do que um agregado de aspecto monolítico. Diversos autores destacam a ligação direta entre grãos como de maior resistência mecânica e de maior resistência à corrosão $[11,12]$. Outros agregados podem ser vistos na microestrutura sem as impurezas mencionadas anteriormente. A análise química via EDS, confirma a pureza desses (ponto 3 na Fig. 4).

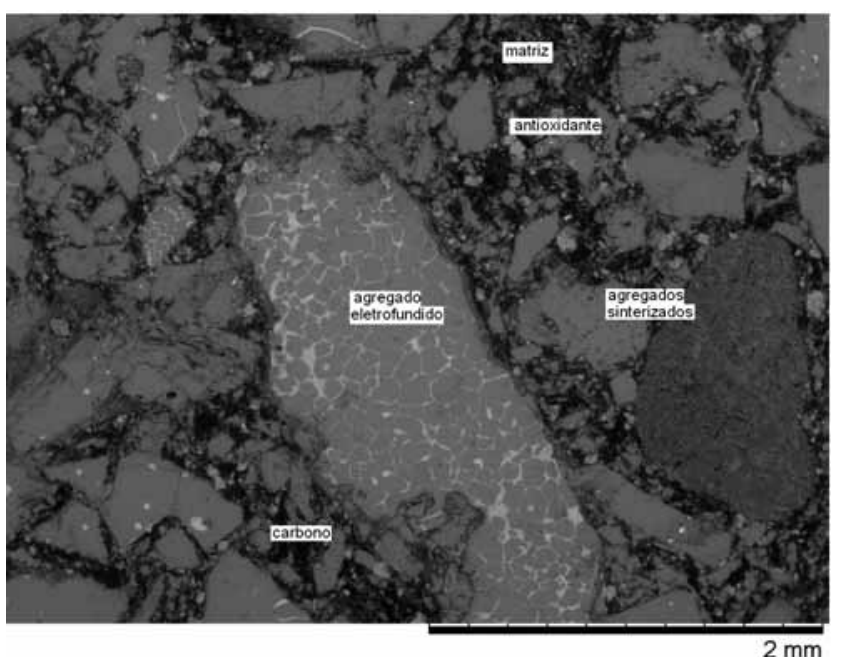

Figura 3: Tijolo MgO-C da linha de metal. $2 \mathrm{~mm}$

[Figure 3: $\mathrm{MgO}$-C metal line brick.]

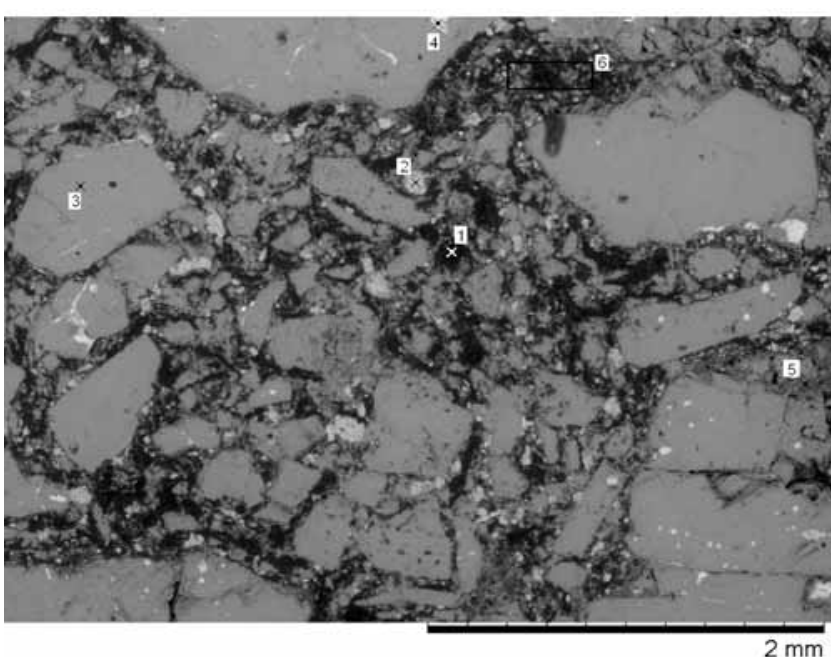

Figura 4: Tijolo MgO-C da linha de metal. Pontos e áreas de análise via EDS (Tabela III).

[Figure 4: $\mathrm{MgO}-\mathrm{C}$ metal line brick. Points and areas of EDS analysis (Table III).]

Tabela III - Análise EDS de acordo com os pontos indicados na Fig. 4. Tijolo MgO-C da linha de metal.

[Table III - Analysis of EDS according to the points indicated in Fig. 4. $\mathrm{MgO}-\mathrm{C}$ metal line brick.]

\begin{tabular}{ccccccc}
\hline $\begin{array}{c}\text { Elementos } \\
(\%)\end{array}$ & 1 & 2 & 3 & 4 & 5 & 6 \\
\hline $\mathrm{Mg}$ & 4,9 & 5,7 & 41,9 & 14,0 & 37,5 & 9,5 \\
$\mathrm{O}$ & 16,2 & 19,6 & 41,6 & 41,9 & 39,5 & 25,7 \\
$\mathrm{C}$ & 77,4 & 26,1 & 11,1 & 9,8 & 20,3 & 60,0 \\
$\mathrm{Al}$ & 1,5 & 48,1 & & 1,5 & 1,3 & 4,0 \\
$\mathrm{Si}$ & & 0,2 & 0,2 & 10,7 & 0,2 & 0,3 \\
$\mathrm{Ca}$ & & & 0,3 & 21,3 & 0,4 & 0,2 \\
Outros & & & $\mathrm{Fe}$ & $\mathrm{P} 0,7$ & $\mathrm{Fe}$ & $\mathrm{Fe}$ \\
& & & 0,6 & & 0,7 & 0,3 \\
\hline
\end{tabular}

A análise em EDS na Fig. 4 e Tabela III identifica os seguintes pontos: 1- Partícula de carbono, como grafite. 2-Partícula de alumínio (antioxidante). 3-Agregado: principalmente magnésio, mas também algumas impurezas como $\mathrm{Si}, \mathrm{Ca}$ e $\mathrm{Fe}$, porém em teores baixos. 4-Impurezas dentro de um agregado, como um silicato de cálcio. 5Agregado: área fraturada com maior teor de impurezas. 6Matriz: principalmente carbono e magnésia. Baixo teor de impurezas como Si e Ca. Apresentou $\mathrm{Al} \sim 4 \%$.

Caracterização dos refratários $\mathrm{MgO}-\mathrm{C}$ da linha de escória

A análise microestrutural do tijolo Mag3 apresentada nas Figs. 5 e 6 mostra uma quantidade significativa de partículas eletrofundidas de elevada resistência à corrosão. Chama a atenção também uma ampla distribuição de carbono ao longo de toda microestrutura e a presença em grande quantidade de antioxidantes. No entanto, os agregados, em 
geral, apresentam repetidamente a presença de impurezas. Estas, conforme a análise em EDS (Fig. 6 e Tabela IV), são ricas principalmente em $\mathrm{Ca}$ e $\mathrm{Si}$, possivelmente, vindo a formar um silicato de menor refratariedade em relação à magnésia. Por outro lado, impurezas de elementos mais fusíveis (alcalinos) não foram encontradas. Com teores mais baixos de magnésia (composição do tijolo: $\mathrm{MgO}$ $78,0-82,0 \%$, C total 13,5-16,5\%, outros máximo 7,0\%), a opção do fabricante foi ressaltar a resistência à oxidação pela presença de antioxidante e garantir uma baixa molhabilidade da escória, com teores elevados de carbono. Esta opção pode ser boa em operações contínuas, mas, se o processo apresentar repetidas paradas com tempos longos de reaquecimento da panela, possivelmente, aumentando a perda de carbono, de modo a expor mais os agregados e a matriz (esta neste caso mais porosa com a perda de muito carbono) ao contato direto com a escória, é possível que o desempenho deste tijolo seja comprometido. Isto limitaria o número de corridas em que ele possa permanecer em uso, sem que a perda de espessura comprometa a segurança operacional.

Face ao discutido anteriormente, é importante ressaltar novamente as diferentes escolhas em relação às

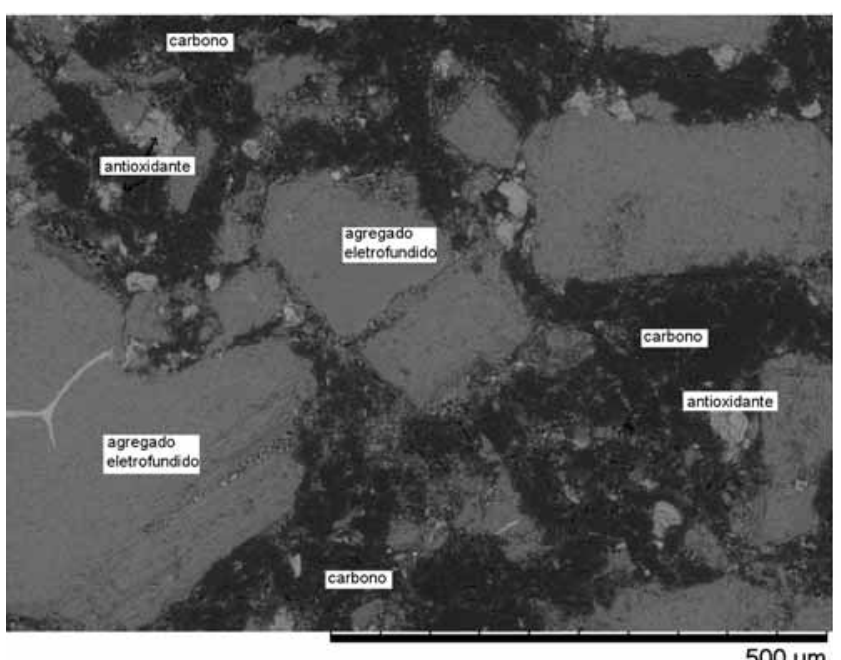

Figura 5: Tijolo MgO-C da linha de escória Mag3.

[Figure 5: MgO-C slag line brick Mag3.]
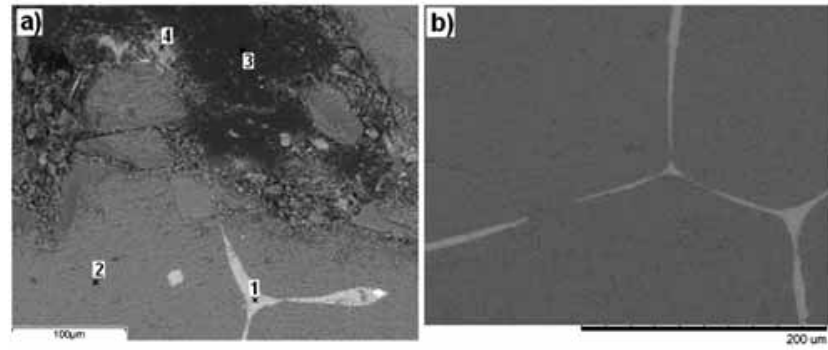

Figura 6: a) Pontos e áreas de análise via EDS do tijolo $\mathrm{MgO}-\mathrm{C}$ da linha de escória Mag3 (Tabela IV). b) Detalhe das impurezas no contorno de grão em agregado eletrofundido.

[Figure 6: a) points and areas of EDS analysis of the $\mathrm{MgO}$-C slag line brick Mag3 (Table IV). b) Detail of impurities in the grain boundary in fused aggregate.] propriedades que se quer atribuir a um refratário. Assim, além de se conhecer as características de um tijolo refratário é preciso conhecer características intrínsecas ao processo no qual o refratário será utilizado. A partir deste preceito, nascem os protótipos e destes as formulações capazes de prover alto desempenho a um custo mais competitivo. Este está diretamente ligado à preparação e pureza das matériasprimas, incluindo-se o beneficiamento, temperatura de calcinação e/ou eletrofusão.

Tabela IV - Análise EDS de acordo com os pontos indicados na Fig. 6. Tijolo MgO-C linha de escória Mag3.

[Table IV-Analysis of EDS according to the points indicated in Fig. 6. Brick $\mathrm{MgO}-\mathrm{C}$ slag line Mag3.]

\begin{tabular}{ccccc}
\hline $\begin{array}{c}\text { Elementos } \\
(\%)\end{array}$ & 1 & 2 & 3 & 4 \\
\hline $\mathrm{Mg}$ & 17,5 & 42,1 & 6,4 & 6,5 \\
$\mathrm{O}$ & 42,0 & 41,0 & 17,3 & 17,0 \\
$\mathrm{C}$ & 14,0 & 15,4 & 75,5 & 40,0 \\
$\mathrm{Al}$ & 0,4 & & & 36,0 \\
$\mathrm{Si}$ & 9,3 & 0,1 & 0,2 & 0,3 \\
$\mathrm{Ca}$ & 16,8 & 0,4 & 0,1 & 0,2 \\
outros & $\mathrm{P} 0,4$ & 1,0 & & \\
\hline
\end{tabular}

A análise em EDS mostra (Fig. 6 e Tabela IV): 1Impurezas dentro do agregado. 2- Agregado, com baixo teor de impurezas. 3- Carbono, como grafite. 4- Antioxidante, Al.

AFig. 6b mostra que as impurezas descritas no ponto $1 \mathrm{da}$ Tabela IV tendem a ficar no espaço intergranular, ocupando os contornos de grão, tipicamente o comportamento de um material de menor ponto de fusão e menor viscosidade em relação a fase magnésia. De acordo com as recomendações da literatura, deve-se utilizar a razão $\mathrm{Ca} / \mathrm{Si}>2$ [2], o que determina a refratariedade da fase formada, embora de menor fundência que a magnésia, ela não deve amolecer

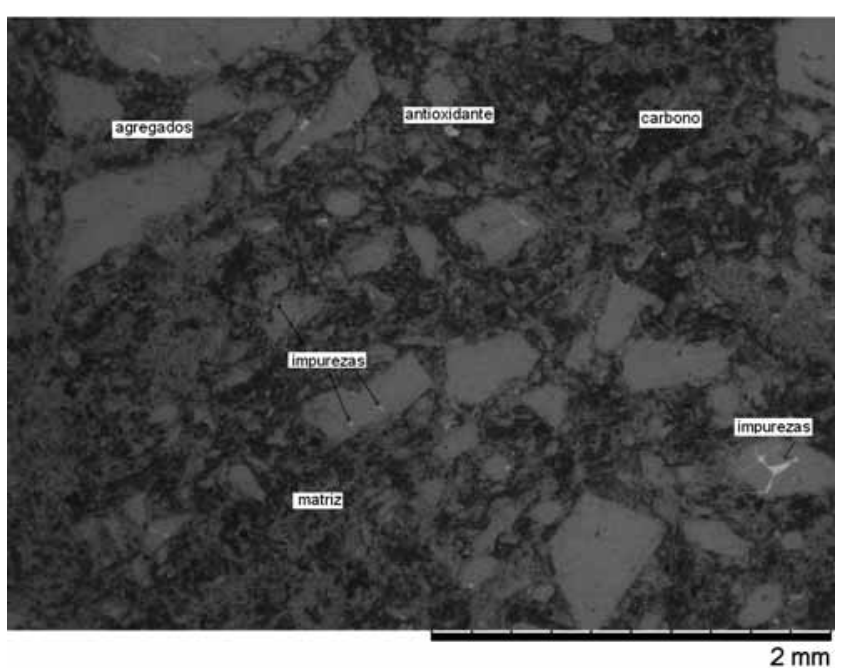

Figura 7: Tijolo MgO-C da linha de escória Mag4.

[Figure 7: $\mathrm{MgO}-\mathrm{C}$ slag line brick Mag4.] 
em serviço. Assim, espera-se a formação de um silicato de alta refratariedade, de acordo com a proporção mostrada na Tabela IV [9].

A microestrutura do tijolo Mag4 apresentada nas Figs. 7 e 8 mostra um refratário com agregados e fase carbono bem dispersos em toda microestrutura. As impurezas igualmente estão presentes, mas notadamente em menor grau em relação ao tijolo anterior (Mag3). Pode-se observar também a presença de grãos eletrofundidos sem nenhuma impureza. Isto confirma as informações do fabricante de ser um tijolo de alta pureza e de $100 \%$ de grãos eletrofundidos.

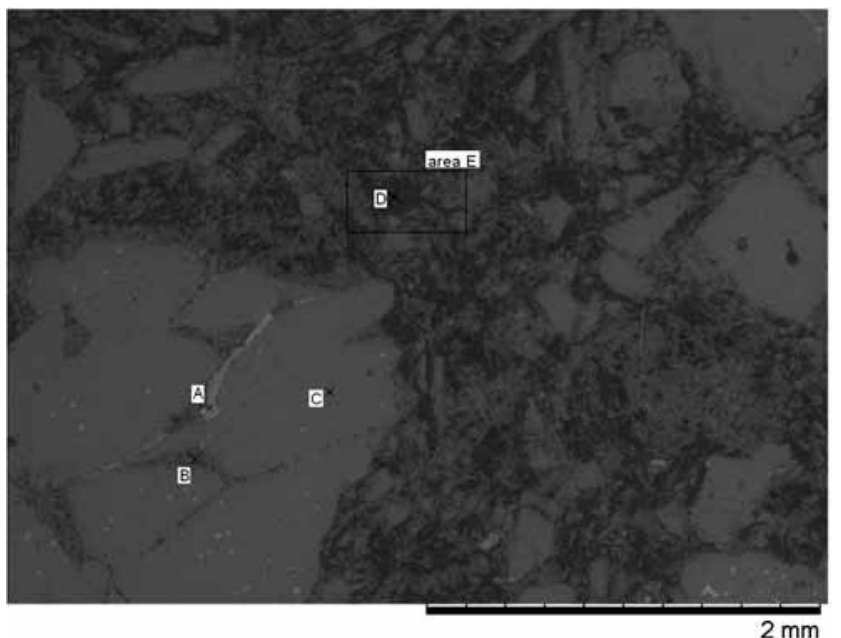

Figura 8: Pontos e áreas de análise via EDS do tijolo $\mathrm{MgO}-\mathrm{C}$ da linha de escória Mag4 (Tabela V).

[Figure 8: Points and areas of EDS analysis of the $\mathrm{MgO}-\mathrm{C}$ brick slag line Mag4 (Table V).]

Tabela V - Análise EDS de acordo com os pontos indicados na Fig. 8. Tijolo MgO-C linha de escória Mag4.

[Table $V$-Analysis of EDS according to the points indicated in Fig. 8. Brick $\mathrm{MgO}$-C slag line Mag4.]

\begin{tabular}{cccccc}
\hline $\begin{array}{c}\text { Elementos } \\
\%\end{array}$ & $\mathrm{~A}$ & $\mathrm{~B}$ & $\mathrm{C}$ & $\mathrm{D}$ & $\begin{array}{c}\text { Área } \\
\mathrm{E}\end{array}$ \\
\hline $\mathrm{Mg}$ & 20,6 & 20,8 & 39,9 & 6,3 & 14,1 \\
$\mathrm{O}$ & 46,4 & 38,8 & 42,6 & 18,8 & 30,9 \\
$\mathrm{C}$ & 14,1 & 29,2 & 16,7 & 73,9 & 53,1 \\
$\mathrm{Al}$ & & 10,1 & 0,3 & & 0,8 \\
$\mathrm{Si}$ & 8,7 & 0,3 & 0,2 & 0,1 & 0,3 \\
$\mathrm{Ca}$ & 9,5 & 0,6 & 0,3 & 0,3 & 0,5 \\
Outros & $\mathrm{Br} 0,7$ & $\mathrm{Ti} 0,2$ & & $\mathrm{Br} 0,6$ & $\mathrm{Fe} 0,1$ \\
\hline
\end{tabular}

Cabe salientar que a escolha dessas características leva intrinsecamente a um tijolo de custo mais elevado.

A análise em EDS, Fig. 8 e Tabela V, mostra: AImpureza dentro do agregado, como um silicato de cálcio. B- Impureza dentro do agregado, rica em alumínio. CAgregado, com baixo teor de impurezas. D- Grafite. EÁrea envolvendo matriz e agregados, mostrando baixo teor de impurezas
Discussão sobre o desempenho dos refratários da linha de escória na prática industrial

Os dois tijolos descritos anteriormente tiverem desempenhos bastante parecidos na prática industrial. Portanto, apesar do tijolo Mag4 possuir maior pureza das matérias-primas, outros aspectos microestruturais fizeramno ter a mesma vida útil do tijolo Mag3, considerando o número de corridas e espessura residual dos tijolos. Os testes foram realizados em longos períodos, minimizandose as variações de processo. Um terceiro tijolo foi testado, denominado Mag5, o qual apresentou melhor desempenho que os anteriores. Este tijolo apresenta propriedades similares ao tijolo Mag4, em termos de pureza de matérias-primas, porosidade e uso de $100 \%$ de magnésia eletrofundida, porém em vez de piche a ligação é por resina. Além deste fator, a microestrutura do Mag5 apresenta uma maior continuidade da fase carbono, com partículas de grafite de tamanho grande (Fig. 9ab). Salienta-se ainda que este refratário não possui antioxidantes. Outra questão importante é a pureza do grafite, que se mostrou elevada, conforme a análise via EDS (Fig. 10). Estas escolhas foram acertadas para a utilização deste refratário para esta aciaria, uma vez que sua vida útil

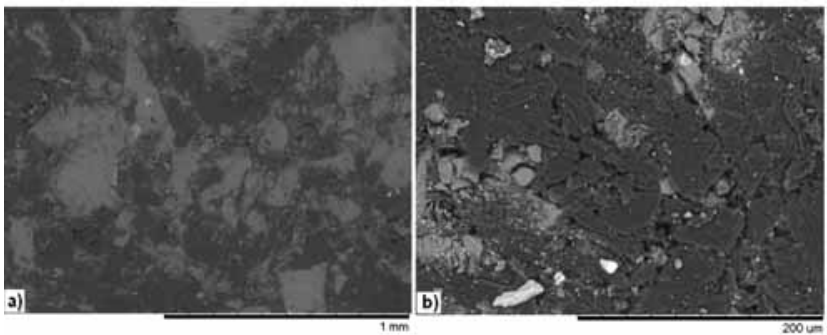

Figura 9: Tijolo MgO-C da linha de escória Mag5. a) aspecto geral da microestrutura. b) detalhe de grãos de grafite.

[Figure 9: Brick $\mathrm{MgO}-\mathrm{C}$ slag line Mag5.a) microstructure overview. $b$ ) detail of graphite grains]

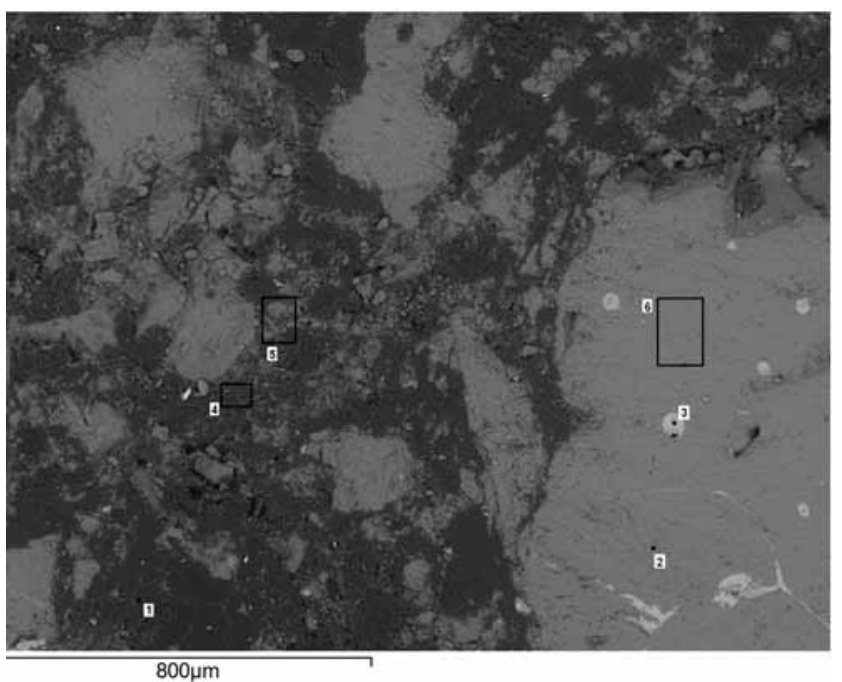

Figura 10: Pontos e áreas de análise via EDS do tijolo $\mathrm{MgO}-\mathrm{C}$ da linha de escória Mag5 (Tabela 5).

[Figure 10: Points and areas of EDS analysis of the $\mathrm{MgO}-\mathrm{C}$ brick slag line Mag5 (Table V).] 
Tabela VI - Análise EDS de acordo com os pontos indicados na Fig. 10. Tijolo MgO-C linha de escória Mag5.

[Table VI - Analysis of EDS according to the points indicated in Fig. 10. Brick MgO-C slag line Mag5.]

\begin{tabular}{ccccccc}
\hline $\begin{array}{c}\text { Elementos } \\
\%\end{array}$ & 1 & 2 & 3 & Área 4 & Área 5 & Área 6 \\
\hline $\mathrm{Mg}$ & 2,9 & 44,6 & 14,5 & 9,8 & 10,5 & 40,1 \\
$\mathrm{O}$ & 9,4 & 40,5 & 41,1 & 22,6 & 23,0 & 39,8 \\
$\mathrm{C}$ & 87,5 & 14,0 & 13,2 & 66,1 & 65,0 & 18,6 \\
$\mathrm{Al}$ & 0,2 & 0,4 & 3,0 & & 0,4 & 0,5 \\
$\mathrm{Si}$ & & & 8,8 & 0,2 & 0,2 & 0,3 \\
$\mathrm{Ca}$ & & 0,4 & 19,5 & 0,6 & 1,1 & 0,7 \\
outros & & & & $\mathrm{Br} 0,8$ & & \\
\hline
\end{tabular}

foi maior que os tijolos testados anteriormente.

A análise em EDS mostra (Fig. 10 e Tabela VI): 1- Grafite com baixo teor de impurezas. 2- Agregado, com baixo teor de impurezas. 3- Impurezas dentro da porosidade fechada em um agregado. 4- Área da matriz, com magnésia e carbono, baixo teor de impurezas. 5- Área da matriz, novamente o teor de impurezas é baixo, embora levemente superior em $\mathrm{Ca}$ e Al, comparando-se com a área anterior. 6- Área em um agregado, baixo teor de impurezas

Caracterização do refratário doloma-C da linha de escória

A microestrutura de um tijolo doloma-C apresenta um aspecto diferente de um tijolo magnésia-C, devido à natureza difásica da doloma. Assim, pode-se observar que as partículas sinterizadas apresentam regiões em que ora predomina a magnésia e ora predomina a cal. A microestrutura consiste de cristalitos de magnésia $(3-5 \mu \mathrm{m})$ em uma matriz de cal $[13,14]$. Os diversos tipos de tijolos variam de composição, podendo ter ligação por piche e/ou resinas, presença de

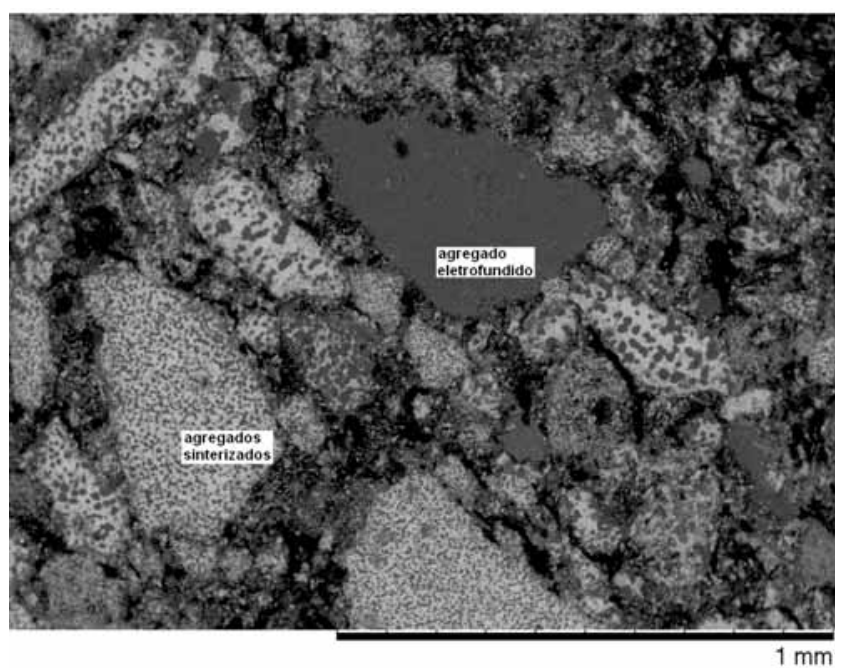

Figura 11: Micrografia MEV do tijolo da linha de escória doloma-C Dol2.

[Figure 11: SEM micrograph of brick doloma-C slag line Dol2.]

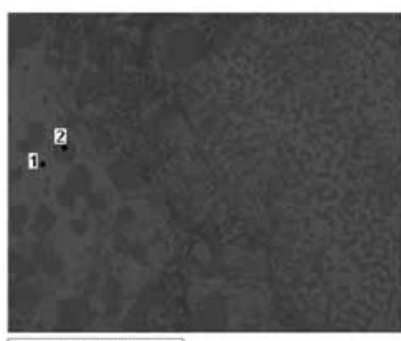

$100 \mu \mathrm{m}$

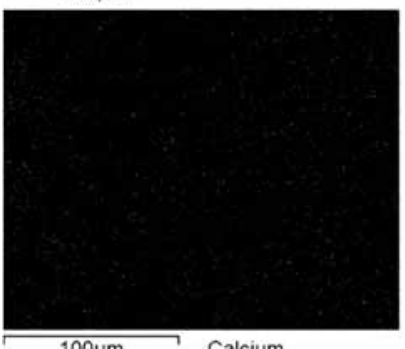

$100 \mu \mathrm{m}$ Calcium

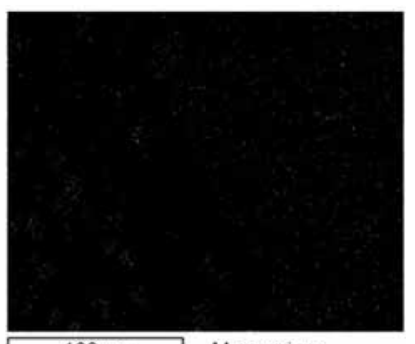

$100 \mu \mathrm{m}$ Magnesium

\begin{tabular}{lll}
\hline $\begin{array}{l}\text { Elementos } \\
\text { (\% peso) }\end{array}$ & Ponto 1 & Ponto 2 \\
\hline Carbono & 9,613 & 14,021 \\
Oxigênio & 38,589 & 41,640 \\
Magnésio & 6,838 & 33,595 \\
Silicio & 0,559 & 0,612 \\
Cálcio & 44,401 & 10,131 \\
\hline
\end{tabular}

Figura 12: Micrografia MEV do tijolo da linha de escória doloma-C Dol2, com análise via EDS.

[Figure 12: SEM micrograph of doloma-C brick slag lineDol2, with EDS analysis.]

carbono pirolítico ou de grafite, variação do teor dessas fases e também a quantidade de magnésia, de modo que alguns tipos são denominados magnésia-doloma. A utilização de partículas eletrofundidas, como em refratários magnésia-C, tem por objetivo o aumento da resistência ao desgaste mecânico e corrosivo.

A Fig. 11 mostra a microestrutura de refratário doloma-C (Dol2) composta por agregados sinterizados e eletrofundidos. Nota-se também a presença de carbono, mas em menor quantidade que a tipicamente utilizada em refratários magnesianos de linha de escória. Na Fig. 12 tem-se as análises de diferentes áreas, mostrando a variação de teor de $\mathrm{Mg}$ ou $\mathrm{Ca}$ por região, como mencionando anteriormente.

Refratários dolomíticos empregados em escórias com sílica devem atua de modo a promover a formação e manutenção da camada protetora de silicato de dicálcio (C2S), a qual atua como uma barreira passivadora em relação à corrosão $[2,3,14]$. Esta camada é característica única deste tipo de tijolo, pois ela é consequência da presença de cal livre no tijolo a qual reage com a sílica presente na escória formando o C2S. Observa-se na prática industrial que tijolos com teores de carbono não tão elevados, de aproximadamente 5\%, apresentam melhor aderência e manutenção deste coating, o que pode levar a uma maior vida útil dos mesmos.

\section{CONCLUSÕES}

Devido às múltiplas escolhas existentes na confecção de um refratário, como o uso de matérias-primas mais puras e eletrofundidas (consequentemente mais caras), podendose ainda variar a distribuição de tamanho de partículas, o tipo de carbono, o sistema de ligação, etc, fazem com 
que a determinação de qual fator é mais relevante ao aumento da resistência à corrosão ser uma tarefa complexa. Muitas vezes, mais de um fator é determinante, atuando sinergicamente com outros parâmetros e dependendo de variáveis como temperatura, tempo de contato e atmosfera do processo, peculiares a uma determinada usina e a cada tipo de aço produzido. Testes de corrosão em laboratório, a caracterização de materiais post-mortem e modelos de simulação podem contribuir encurtando caminhos à solução, além de oferecer opções de testes sem risco industrial. No entanto, eles ainda estão longe de resolver plenamente o problema, como se pode ver na literatura especializada, mencionada no presente trabalho. Assim, é fundamental a relação fornecedor-consumidor no desenvolvimento de uma estratégia conjunta de aprimoramento dos materiais refratários, já que a performance desses dependem fortemente das condições experimentais em sua aplicação industrial. A caracterização da microestrutura de refratários, como realizada neste trabalho, relacionando-se com o desempenho do tijolo no uso industrial, pode ser bastante importante à compreensão do tema, fornecendo subsídios a uma melhor escolha dos diversos parâmetros na manufatura e uso de refratários.

\section{REFERÊNCIAS}

[1] D. A. Brosnan, Corrosion of refractories, in: Refractories Handbook, Ed. Schatcht, C.A., Marcel Dekker INC., New York, EUA (2004) 39.

[2] S. R. Bragança, "Aspectos Teóricos e Práticos Sobre a Corrosão de Refratários Utilizados na Siderurgia. Parte 1: Propriedades Microestruturais", Cerâmica 58, 347 (2012) 280-285.

[3] S. R. Bragança, "Aspectos Teóricos e Práticos sobre a Corrosão de Refratários Utilizados na Siderurgia.
Parte 2: Propriedades Físicas dos Refratários e Fatores Operacionais", Cerâmica 58, 347 (2012) 459-464.

[4] ASTM C133-97, Standard test methods for cold crushing strength and modulus of rupture of refractories, ASTM American Society for Testing and Materials, USA, Book of Standards v. 15.01 (2003).

[5] ASTM C20-00, Standard test methods for apparent porosity, liquid absorption, apparent specific gravity, and bulk density of burned refractory brick and shape by boiling water, ASTM - American Society for Testing and Materials, USA, Book of Standards, v. 15.01 (2005).

[6] ASTM C1171, Standard Test Method for Quantitatively Measuring the Effect of Thermal Shock and Thermal Cycling on Refractories. ASTM - American Society for Testing and Materials, USA, Book of Standards Volume: 15.01 (1996).

[7] A. M. Segadães, Refractários, Universidade de Aveiro, Portugal (1997) 65.

[8] S. Jansson, V. Brabie, P. Jönsson, Scandinavian J. Metallurgy 34 (2005) 283-292.

[9] W. E. Lee, S. Zhang, Int. Mater. Rev. 44, 3 (1999) 77104.

[10] W. E Lee, S. Zhang, VII Int. Conf. Molten Slags, Fluxes and Salts, The South African Institute of Mining and Metallurgy (2004) 309-319.

[11] R. A. Mattila, J. P. Vatanen, J. J. Harkki, Scandinavian J. Metallurgy 31 (2002) 241-245.

[12] S. C. Carniglia, G.L. Barna, Handbook of industrial refractories technology: principles, types, properties and applications, Noyes Publ., Park Ridge, NJ, EUA (1992).

[13] S. Jansson, V. Brabie, P. Jönsson, Ironmaking Steelmaking 5, 2 (2008) 99-107.

[14] C. Richmond, Doloma refractories, in: Refractories Handbook, Ed. Schatcht, C.A., Marcel Dekker INC., New York, EUA (2004) 183.

(Rec. 12/12/2011, Rev. 16/02/2012, Ac. 19/04/2012) 